\title{
Pharmacotherapy for alcohol use disorder in patients with hepatic impairment
}

\author{
Courtney V. Eatmon, PharmD, BCPP, and Kelley Trent, PharmD
}

$\mathrm{M}$ r. S, age 64 , presents for an outpatient follow-up after a recent hospital discharge for alcohol detoxification. He reports a long history of alcohol use, which has resulted in numerous hospital admissions. He has recently been receiving care from a gastroenterologist because the results of laboratory testing suggested hepatic impairment (Table 1, ${ }^{1}$ page 26). Mr. S says that an friend of his was able to stop drinking by taking a medication, and he wonders if he can be prescribed a medication to help him as well.

A chart review shows that Mr. $S$ recently underwent paracentesis, during which 6 liters of fluid were removed. Additionally, an abdominal ultrasound confirmed hepatic cirrhosis.

According to the World Health Organization, alcohol consumption contributes to 3 million deaths annually. ${ }^{2}$ The highest proportion of these deaths $(21.3 \%)$ is due to alcoholassociated gastrointestinal complications, including alcoholic and infectious hepatitis, pancreatitis, and cirrhosis. Because the liver is the primary site of ethanol metabolism, it sustains the greatest degree of tissue injury with heavy alcohol consumption. Additionally, the association of harmful use of alcohol with risky sexual behavior may

Dr. Eatmon is Clinical Pharmacy Specialist, Substance Use Disorders, Lexington Veterans Affairs Health Care System, and Assistant Professor, Department of Pharmacy Practice and Science, University of Kentucky, Lexington, Kentucky. Dr. Trent is a PGY-2 Psychiatric Pharmacy Resident, Lexington Veterans Affairs Health Care System, Lexington, Kentucky.

\section{Disclosures}

The authors report no financial relationships with any companies whose products are mentioned in this article, or with manufacturers of competing products.

doi: $10.12788 /$ cp.0068 partially explain the higher prevalence of viral hepatitis among persons with alcohol use disorder (AUD) compared with the general population. Alcoholic liver disease (ALD) progresses through several stages, beginning with hepatic steatosis and progressing through alcohol-related hepatitis, fibrosis, cirrhosis, and potentially hepatocellular carcinoma. ${ }^{3}$

\section{Liver markers of alcohol use}

Although biological markers can be used in clinical practice to screen and monitor

\section{Practice Points}

- The risk of alcoholic liver disease (ALD) increases with daily alcohol consumption; however, it is also dependent on genetic predisposition, age, gender, comorbid hepatitis B or $C$ infection, and other risk factors.

- Liver function tests must be interpreted carefully along with a full clinical picture because these tests are not specific to liver injury, and the degree of liver enzyme elevation does not always correspond with the degree of liver injury.

- Although not specific, alterations in serum albumin level and international normalized ratio are better correlated to actual liver function as the disease progresses.

- Of the 3 FDA-approved medications for the treatment of alcohol use disorder, only acamprosate is considered safe for use in patients with severe ALD.

- Baclofen is the only medication that has been tested specifically in patients with advanced ALD and may promote abstinence and reduce return to use.

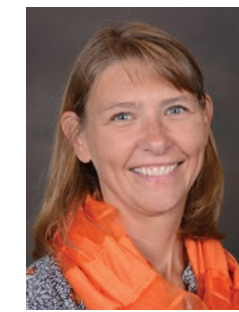

Vicki L. Ellingrod, PharmD, FCCP

Department Editor
Savry Psychopharmacology is produced in partnership with the College of Psychiatric and Neurologic Pharmacists cpnp.org mhc.cpnp.org (journal) 


\section{Clinical Point}

\section{The risk of}

alcoholic liver

disease increases

with daily alcohol

consumption, but

also depends on

other risk factors

Discuss this article at www.facebook.com/ MDedgePsychiatry

\section{Table 1}

\section{Hepatic laboratory values for Mr. S}

\begin{tabular}{l|l|l}
$\begin{array}{l}\text { Liver } \\
\text { function test }\end{array}$ & $\begin{array}{l}\text { Mr. S's } \\
\text { values }\end{array}$ & $\begin{array}{l}\text { Reference } \\
\text { range }\end{array}$ \\
\hline AST & $216 \mathrm{U} / \mathrm{L}$ & 17 to $59 \mathrm{U} / \mathrm{L}$ \\
\hline ALT & $99 \mathrm{U} / \mathrm{L}$ & 20 to $35 \mathrm{U} / \mathrm{L}$ \\
\hline ALP & $194 \mathrm{U} / \mathrm{L}$ & 44 to $147 \mathrm{U} / \mathrm{L}$ \\
\hline GGT & $76 \mathrm{U} / \mathrm{L}$ & 9 to $48 \mathrm{U} / \mathrm{L}$ \\
\hline Total bilirubin & $1.6 \mathrm{mg} / \mathrm{dL}$ & 0.2 to $1.3 \mathrm{mg} / \mathrm{dL}$ \\
\hline $\begin{array}{l}\text { ALP: alkaline phosphatase; ALT: alanine aminotransferase; } \\
\text { AST: aspartate aminotransferase; GGT: gamma-glutamyl } \\
\text { transferase }\end{array}$ \\
Source: Reference 1
\end{tabular}

for alcohol abuse, making a diagnosis of ALD can be challenging. Typically, a history of heavy alcohol consumption in addition to certain physical signs and laboratory tests for liver disease are the best indicators of ALD. However, the clinical assessment can be confounded by patients who deny or minimize how much alcohol they have consumed. Furthermore, physical and laboratory findings may not be specific to ALD.

Liver enzymes, including aspartate aminotransferase (AST), alanine aminotransferase (ALT), and gamma-glutamyltransferase (GGT), have historically been used as the basis of diagnosing ALD. In addition to elevated bilirubin and evidence of macrocytic anemia, elevations in these enzymes may suggest heavy alcohol use, but these values alone are inadequate to establish ALD. Gamma-glutamyltransferase is found in cell membranes of several body tissues, including the liver and spleen, and therefore is not specific to liver damage. However, elevated GGT is the best indicator of excessive alcohol consumption because it has greater sensitivity than AST and ALT. ${ }^{1,3,4}$

Although these biomarkers are helpful in diagnosing ALD, they lose some of their utility in patients with advanced liver disease. Patients with severe liver dysfunction may not have elevated serum aminotransferase levels because the degree of liver enzyme elevation does not correlate well with the severity of ALD. For example, patients with advanced cirrhosis may have liver enzyme levels that appear normal. However, the pattern of elevation in transaminases can be helpful in making a diagnosis of liver dysfunction; using the ratio of AST to ALT may aid in diagnosing ALD, because AST is elevated more than twice that of ALT in $>80 \%$ of patients with ALD. ${ }^{1,3,4}$

Table 2,13,4 (page 27) shows the progression of ALD from steatohepatitis to alcoholic hepatitis to cirrhosis. In steatohepatitis, transaminitis is present but all other biomarkers normal. In alcoholic hepatitis, transaminitis is present along with elevated alkaline phosphatase, elevated bilirubin, and elevated international normalized ratio (INR). In alcoholic cirrhosis, the ASTto-ALT ratio is $>2$, and hypoalbuminemia, hyperbilirubinemia, and coagulopathy (evidenced by elevated INR) are present, consistent with long-term liver damage. ${ }^{13,4}$

\section{FDA-approved medications}

Three medications-acamprosate, naltrexone, and disulfiram-currently are FDAapproved for treating AUD. ${ }^{5,6}$ Additionally, several other medications have shown varying levels of efficacy in treating patients with AUD but are not FDA-approved for this indication (Table $3{ }^{5-8}$ page 28 ).

Acamprosate is thought to create a balance of inhibitor and excitatory neurotransmitters by functioning as a glutamate antagonist and gamma-aminobutyric acid (GABA) agonist. This is speculated to aid in abstinence from alcohol. Data suggests that acamprosate may be more effective for maintaining abstinence than for inducing remission in individuals who have not yet detoxified from alcohol. Because of its renal excretion, acamprosate is the only FDA-approved medication for AUD that is not associated with liver toxicity. The most commonly reported adverse effect with acamprosate use is diarrhea.

Naltrexone, a mu-opioid receptor antagonist, is available in both tablet and long-acting IM injection formulations. Naltrexone blocks the binding of endorphins created by alcohol consumption to opioid receptors. 


\section{Progression of alcoholic liver disease}

\begin{tabular}{|c|c|c|c|}
\hline Liver function test & Alcoholic steatohepatitis & Alcoholic hepatitis & Alcoholic cirrhosis \\
\hline AST & $174 \mathrm{U} / \mathrm{L}(\mathrm{H})$ & $260 \mathrm{U} / \mathrm{L}(\mathrm{H})$ & $109 \mathrm{U} / \mathrm{L}(\mathrm{H})$ \\
\hline ALT & $86 \mathrm{U} / \mathrm{L}(\mathrm{H})$ & $94 \mathrm{U} / \mathrm{L}(\mathrm{H})$ & $39 \mathrm{U} / \mathrm{L}$ \\
\hline ALP & $87 \mathrm{U} / \mathrm{L}$ & $192 \mathrm{U} / \mathrm{L}(\mathrm{H})$ & $169 \mathrm{U} / \mathrm{L}(\mathrm{H})$ \\
\hline GGT & $52 \mathrm{U} / \mathrm{L}(\mathrm{H})$ & $94 \mathrm{U} / \mathrm{L}(\mathrm{H})$ & 204 U/L (H) \\
\hline Total protein & $6.6 \mathrm{gm} / \mathrm{dL}$ & $8.6 \mathrm{gm} / \mathrm{dL}(\mathrm{H})$ & $6.7 \mathrm{gm} / \mathrm{dL}$ \\
\hline Albumin & $3.7 \mathrm{~g} / \mathrm{dL}$ & $4.6 \mathrm{~g} / \mathrm{dL}$ & $2.8 \mathrm{~g} / \mathrm{dL}(\mathrm{L})$ \\
\hline Total bilirubin & $1.0 \mathrm{mg} / \mathrm{dL}$ & $1.8 \mathrm{mg} / \mathrm{dL}(\mathrm{H})$ & $3.8 \mathrm{mg} / \mathrm{dL}(\mathrm{H})$ \\
\hline INR & 1.11 & 1. $3(\mathrm{H})$ & $2.45(\mathrm{H})$ \\
\hline
\end{tabular}

This results in diminished dopamine release and is speculated to decrease reward and positive reinforcement with alcohol consumption, leading to fewer heavy drinking days. Due to hepatic metabolism, naltrexone use carries a risk of liver injury. Cases of hepatitis and clinically significant liver dysfunction as well as transient, asymptomatic, hepatic transaminase elevations have been observed in patients who receive naltrexone. Because of the absence of firstpass metabolism, long-acting IM naltrexone may produce less hepatotoxicity than the oral formulation. When the FDA approved both formulations of naltrexone, a "blackbox" warning was issued concerning the risk of liver damage; however, these warnings have since been removed from their respective prescribing information.

Disulfiram inhibits acetaldehyde dehydrogenase, resulting in elevated acetaldehyde concentrations after consuming alcohol. In theory, this medication reduces a person's desire to drink due to the negative physiological and physical effects associated with increased acetaldehyde, including hypotension, flushing, nausea, and vomiting. Although most of these reactions are shortlived, disulfiram can induce hepatotoxicity and liver failure that may prove fatal. Disulfiram should be avoided in patients with advanced ALD.

\section{Off-label medications for AUD}

Additional pharmacotherapeutic agents have been evaluated in patients with AUD. Baclofen, topiramate, gabapentin, and ondansetron have shown varying levels of efficacy and pose minimal concern in patients with ALD.

Baclofen. Although findings are conflicting, baclofen is the only agent that has been specifically studied for treating AUD in patients with ALD. A GABA B receptor antagonist, baclofen is currently FDAapproved for treating spasticity. In a series of open-label and double-blind studies, baclofen has been shown to effectively reduce alcohol intake, promote abstinence, and prevent relapse., ${ }^{5,6}$ Further studies identified a possible dose-related response, noting that $20 \mathrm{mg}$ taken 3 times daily may confer additional response over $10 \mathrm{mg}$ taken 3 times daily, ${ }^{5,6}$ Conversely, the ALPADIR study failed to demonstrate superiority of baclofen vs placebo in the maintenance of abstinence from alcohol despite dosing at $180 \mathrm{mg} / \mathrm{d} .^{9}$ This study did, however, find a significant reduction in alcohol craving in favor of baclofen. ${ }^{9}$ Further, in a randomized controlled trial (RCT) conducted in veterans with chronic hepatitis $\mathrm{C}$, baclofen 30 $\mathrm{mg} / \mathrm{d}$ failed to show superiority over placebo with regard to increasing abstinence or reducing alcohol use. ${ }^{10}$

\section{Clinical Point}

Liver function tests must be interpreted carefully along with a full clinical picture because these tests are not specific to liver injury 
Clinical Point

Of the 3 medications FDA-approved for alcohol use disorder, only acamprosate is considered safe for use in patients with severe ALD

\section{Table 3}

Medications for treating alcohol use disorder

\begin{tabular}{|c|c|c|}
\hline Medication & Dosing information & $\begin{array}{l}\text { Appropriate in alcoholic } \\
\text { liver disease? }\end{array}$ \\
\hline \multicolumn{3}{|c|}{ FDA-approved medications } \\
\hline \multirow[t]{3}{*}{ Acamprosate } & 666 mg 3 times daily & \multirow[t]{3}{*}{ Yes } \\
\hline & $\begin{array}{l}\mathrm{CrCl} 30 \text { to } 50 \mathrm{~mL} / \mathrm{min}: \\
333 \mathrm{mg} 3 \text { times daily }\end{array}$ & \\
\hline & $\mathrm{CrCl} \leq 30 \mathrm{~mL} / \mathrm{min}$ : contraindicated & \\
\hline Naltrexone, oral & $50 \mathrm{mg} / \mathrm{d}$ & \multirow{2}{*}{$\begin{array}{l}\text { Not recommended for use in } \\
\text { patients with acute hepatitis or } \\
\text { hepatic failure }\end{array}$} \\
\hline $\begin{array}{l}\text { Naltrexone suspension, } \\
\text { intramuscular }\end{array}$ & $380 \mathrm{mg}$ once every 4 weeks & \\
\hline Disulfiram & 125 to $500 \mathrm{mg} / \mathrm{d}$ & $\begin{array}{l}\text { Avoid use in patients with } \\
\text { advanced ALD }\end{array}$ \\
\hline \multicolumn{3}{|l|}{ Off-label medications } \\
\hline Baclofen & $\begin{array}{l}10 \mathrm{mg} 3 \text { times daily; } \\
\text { maximum dose: } 15 \mathrm{mg} 3 \text { times daily }\end{array}$ & Yes \\
\hline Topiramate & 75 to $300 \mathrm{mg} / \mathrm{d}$ & $\begin{array}{l}\text { Yes, clearance may be } \\
\text { reduced in hepatic impairment } \\
\text { Use with caution in hepatic } \\
\text { encephalopathy }\end{array}$ \\
\hline Gabapentin & 900 to $1,800 \mathrm{mg} / \mathrm{d}$ & Yes \\
\hline Ondansetron & $4 \mathrm{mcg} / \mathrm{kg}$ twice daily & $\begin{array}{l}\text { Yes, use with caution because } \\
\text { liver toxicity has been reported }\end{array}$ \\
\hline
\end{tabular}

Topiramate. A recent meta-analysis found that topiramate use may result in fewer drinking days, heavy drinking days, and number of drinks per drinking day. ${ }^{7}$ Additionally, topiramate has demonstrated a statistically significant reduction in alcohol craving as well as the ability to decrease all liver function test values. ${ }^{5}$ This agent should be used with caution in patients with hepatic encephalopathy because the adverse cognitive effects associated with topiramate may confound the clinical course and treatment of such.

Gabapentin. The use of gabapentin to treat patients with AUD is supported by multiple RCTs. In studies that evaluated dose-related response, higher doses of gabapentin (up to $1,800 \mathrm{mg} / \mathrm{d}$ ) showed greater efficacy than lower doses (ie, $900 \mathrm{mg} / \mathrm{d}$ ). ${ }^{8}$ Because gabapentin does not undergo hepatic metabolism, its use in patients with ALD is considered safe. Although the abuse potential of gabapentin is less defined in patients with AUD, there have been reports of abuse in other high-risk populations (ie, those with opioid use disorder, incarcerated persons, and those who misuse prescriptions recreationally). ${ }^{8}$

Ondansetron is speculated to decrease the reward from alcohol via the down-regulation of dopaminergic neurons. Studies examining ondansetron for patients with AUD have found that it decreases alcohol cravings in those with early-onset alcoholism (initial onset at age $\leq 25$ ), but not in late-onset alcoholism (initial onset at age $>25$ ). ${ }^{5}$ However, the ondansetron doses used in these trials were very low $(4 \mathrm{mcg} / \mathrm{kg}$ ), and those doses are not available commercially. ${ }^{5}$

\section{CASE CONTINUED}

Following a discussion of available pharmacotherapeutic options for AUD, Mr. S is started on baclofen, $10 \mathrm{mg} 3$ times daily, with plans for dose titration. At a 2-week follow-up appointment, Mr. S reports that he had not been taking baclofen as often as instructed; however, 
he denies further alcohol consumption and recommits to baclofen treatment. Unfortunately, Mr.S is soon admitted to hospice care due to continued decompensation and is unable to attend any additional outpatient follow-up appointments. Three months after his initial outpatient contact, Mr. S dies due to alcoholic cirrhosis.

\section{References}

1. Agrawal S, Dhiman RK, Limdi JK. Evaluation of abnormal liver function tests. Postgrad Med J. 2016;92(1086):223-234.

2. World Health Organization. Global status report on alcohol and health 2018. Published 2018. Accessed November 5, 2020. https://www.who.int/substance_abuse/publications/global_ alcohol_report/gsr_2018/en/

3. Osna NA, Donohue TM, Kharbanda KK. Alcoholic liver disease: pathogenesis and current management. Alcohol Res. 2017;38(2):147-161

4. Leggio L, Lee MR. Treatment of alcohol use disorder in patients with alcoholic liver disease. Am J Med. 2017;130(2):124-134.

5. Addolorato G, Mirijello A, Leggio L, et al. Management of alcohol dependence in patients with liver disease. CNS Drugs. 2013;27(4):287-299.

6. Vuittonet $\mathrm{CL}$, Halse M, Leggio L, et al. Pharmacotherapy for alcoholic patients with alcoholic liver disease. Am J Health Syst Pharm. 2014;71(15):1265-1276.

7. Jonas DE, Amick HR, Feltner C, et al. Pharmacotherapy for adults with alcohol use disorders in outpatient settings. JAMA. 2014;311(18):1889-1900.

\section{Related Resources}

- Crabb DW, Im GY, Szabo G, et al. Diagnosis and treatment of alcohol-related liver diseases: 2019 practice guidance from the American Association for the Study of Liver Diseases. Hepatology. 2020;71(1):306-333.

- Murail AR, Carey WD. Disease management. Liver test interpretation - approach to the patient with liver disease: a guide to commonly used liver tests. Cleveland Clinic Center for Continuing Education. Updated August 2017. www.clevelandclinicmeded. com/medicalpubs/diseasemanagement/hepatology/ guide-to-common-liver-tests/

Drug Brand Names

Acamprosate - Campral Naltrexone $\cdot$ Revia, Vivitrol

Baclofen • Lioresal Ondansetron - Zofran

Disulfiram - Antabuse Topiramate · Topamax

Gabapentin • Neurontin

8. Mason BJ, Quello S, Shadan F. Gabapentin for the treatment of alcohol use disorder. Expert Opin Investig Drugs. 2018; 27(1):113-124.

9. Reynaud M, Aubin HJ, Trinquet F, et al. A randomized, placebocontrolled study of high-dose baclofen in alcohol-dependent patients-the ALPADIR study. Alcohol Alcohol. 2017;52(4): 439-446.

10. Hauser P, Fuller B, Ho S, et al. The safety and efficacy of baclofen to reduce alcohol use in veterans with chronic hepatitis C: a randomized controlled trial. Addiction. 2017;112(7):1173-1183
Clinical Point

\section{Baclofen may} promote abstinence and reduce return to alcohol use in patients with advanced ALD 